\title{
A Sociological Study on Arthur Miller's Death of a Salesman and All My Sons, Based on Georgy Lukacs's Theories
}

\author{
Fatemeh Pakdaman Shahri ${ }^{1}$ \\ ${ }^{1}$ Art University of Tehran, Tehran, Iran \\ Correspondence: Fatemeh Pakdaman Shahri, Art University of Tehran, Tehran, Iran. E-mail: \\ sara.pakdaman7@gmail.com
}

Received: September 27, 2017

Accepted: October 9, 2017 Online Published: November 8, 2017

doi:10.5539/res.v9n4p83

URL: http://doi.org/10.5539/res.v9n4p83

\begin{abstract}
Society and its human relations have always had a mutual connection with arts and culture; thus, the majority of artistic creations have always reflected images of society in the very heart of them. Sociological Studies of art, as an independent field does have a long history, however with the rise of modern social fields of study in the $19^{\text {th }}$ and $20^{\text {th }}$ century, there has been a significant growth in sociological studies.

Georgy Lukacs as a pioneer theorist in the sociology of arts and literature has led a series of studies in the field of modern drama. This study has attempted to analyze Arthur Miller's two significant plays, Death of a Salesman and All My Sons, based on Lukacs's theories, along with discovering the methods, which Miller has depicted to process and interweave social concepts and phenomena within his works. This being done, a potential map has been drawn as a clear sample for dramatists of the modern era of playwriting on how to relate to social and cultural issues, not only in a descriptive method but in an analytical, critical way.
\end{abstract}

Keywords: Arthur Miller, drama sociology, drama criticism, Georgy Lukacs, sociological theory

\section{Introduction}

Drama and specifically tragedy, from the very beginning of their creation, have had a close connection with the social, political, and also epistemological grounds of their very own geographical region. On the other hand, some believe that the very sociological backgrounds of each and every society have been the main reason for the emergence of infinite varieties in modern drama.

The main focus of this study has been in the analysis of sociological aspects of drama, specifically modern drama; in other words, the routs sociological phenomena take, through which they emerge in the context of modern drama. Can sociological grounds in a work of art be seen as laid out patterns against the playwright's will? Or is it the playwright him/herself that sets out to portray their very pattern in the literary work?

Arthur Miller, that is one of the most prominent writers of modern drama, is a perfect example of the kind. Not only does he mirror numerous variations of sociological and political aspects in his work, but he takes the position of a strong critic. He analyzes and criticizes various life aspects of his people, and the consequences people have to face due to their choice of life and ideology in his plays. Another question then rises, whether Miller has chosen a specific ideology of his time to narrate what goes on in his time, or as a playwright he has tried to wear his very personal glasses, through which he looks at the world around and shares with us his perspective.

Georgy Lukacs, a leading critic, and theorist both in philosophy and sociology has had a number of well-formed, influential articles, attributed to the subject of tragedy and modern drama. In his articles, he has valued a critical, sociological view of an artist, who attempts to awaken his audience's sociological and class awareness. The stance Lukacs has taken is paralleled with that of Miller's. It seems that they are both on the same page regarding the issues of clinging to art as a tool for the awareness of masses.

This study is to go through the two masterpieces of Miller's All My Sons and Death of a Salesman on a sociological approach closely, to deconstruct the ways modern drama has made itself thoroughly interrelated to our lives. Lukacs's theories on how this happens and indeed, how this should happen shed light on a new path to be taken in contemporary drama, by their creators. 
Since the final decades of the nineteenth century, along with the emergence of sociology as a leading branch of humanities, the pioneers in this field have attempted to define abstract concepts such as: society, culture, sociological actions, and also define a limit to the borders of the field of sociology, in order to set a concrete basis for it. This attempt, of course, has not been successful, since, in the following years, many a philosophers and theorists have done a lot of studies in sociology, which has actually led to the extension of the borders of this field, failing each and every time to limit its territory.

Culture, on the other hand, consists of deep layers, actions, and interpersonal relationships, not much crystal clear to conceive and decipher, regarding their very nature and mechanisms. Tylor defines culture: "Culture is a complex set of knowledge, beliefs, arts, morals, rules, and customs, and any kind of potential and habits-any single trait-, which human being, as members of a single society achieve" (Tylor, 1974, p. 11). In another word, culture is all based on which, one constitutes their relationship with society.

It seems like an undeniable fact that nowadays culture is attributed to what one perceives of the meaning of life in general. Levi-Strauss argues: "Human being is a biological entity, as well as a sociological one. Among the reactions, one decides to perform, some are definite productions of his nature, and the rest are the products of his situation, context... It is not always easy to distinguish between these two types of reactions. Culture is neither paralleled with, nor conjoined to life, but it replaces life itself. It takes life, deconstructs it in order to purify and synthesize it" (Levi-Strauss, 1969, p. 41). This new understanding, without doubt, should be counted as a true product of the development of sociology, and prior to that, the development of humanities in different disciplines.

\section{The History of Sociology}

"Sociology" a Barbarian term, first used by Auguste Comte to refer to this field of study, is made up of the Latin word "socius", meaning society and the Greek word "logus", meaning studies of high rank and of high value. Although the progress of sociology is a direct outcome of the industrial revolution, many consider Comte to be the founder of this field.

Consequent to overcoming the hardships of the $19^{\text {th }}$ century, especially the ones that pertained to social issues, there was a great chance for philosophers like Karl Marx to nurture this newly born field. Besides from him, Emile Durkheim and Max Weber have tried to define doctrines for sociology, based on which a better analysis and understanding of human society can be made possible. Herbert Spencer in Britain has done a great deal in the development of sociology, due to his critical ideas against the dominant doctrines in his time; he was fore leissez-faire, that is the policy of leaving things to take their own courses, without interfering.

Sociology is more of a doctrine to analyze various fields of thoughts in a society and interpersonal relationships among human beings, as well as their connections with economics and politics. Weber might have been the one, who has defined sociology in a thorough way: "It is a knowledge that attempts to achieve a thorough understanding of a social act so that we can be able to explain temporarily, how society works and how we are affected by it" (Weber, 2012, p. 88). By a social act, he means the kind of actions that are in close connections with those of other members of the same society.

\subsection{Sociology of Arts and Literature}

Contrary to what might seem at the first glance, sociology of arts and literature has never been just a subcategory of a larger domain, that is sociology, but it has been an immediate, prerequisite portion of what we call art. In other words, sociology of arts and literature has been an area, existing at the very beginning of any production of any work of art, since more often than never it is an immediate instinct of art to analyze and criticize its social context; a notion only a small number of authors artists could have escaped bearing in mind. As a result, artists have not only created arts, but they have also been the very first critics of their societies.

Although the theoretical aspect of the sociology of arts and literature has had a long history since Greek philosophers, especially in Aristotle's texts and talks, the very first autonomous actions through the integration of this field of criticism takes place in the $19^{\text {th }}$ century. One of the determining changes in Europe, leading to the integration of this domain, hence the sudden mass attention of artists and critics to it, is the industrial revolution. This belief that literature is to narrate major events of its time is a consequence to the revolution, which gains many of its advocates in the beginning of the $19^{\text {th }}$ century. The reason for this turning point was the dominant depression of the time, which redirects the path of arts and literature significantly.

Madame De Stael, the French political activist, and historiographer, is among the first to define the socio-historical stance and status of characters, the significance of literature, national French figures, and also led a series of comparative studies of literary works of her time with the ones of the classic era; thus, she has been a 
pioneer in the sociology of arts and literature. She strongly believed that literature is not just a form of art anymore, but a medium to perceive, to act, and to fight back. Hippolyte Taine, a French literary critic, and philosopher, is the first to introduce the sociological approach as a subcategory of literary criticism in The History of English Literature.

Consequent to these attempts, along with the advancements of aesthetics, Kant, Hegel, and also other theorists in history, philosophy, and psychology, then direct their attention to the development of literary criticism.

Under the influence of Marxist theorists, who considered arts and literature the immediate reproduction of society, a close connection between this movement and literature then, was formed. Although most Marxist theorists overlooked the aesthetics of literature, they were the very reason for the formation of many ideas of the sociology of arts and literature.

\subsection{Sociological Approach in the Analysis of Drama}

Without a doubt, there is no form of art like drama, that has succeeded in being this interrelated with social practices of life. Although drama, in ancient times, was restricted to Greece, rarest civilizations can be found lacking this form of art, that is drama. Georges Gurvitch in the Sociology of Drama argues, drama represents a social situation and gathering in its common sense. Drama in its own turn creates a social frame, in which the actors and actresses are the complementary parts. We go to the theatre to re-experience the social experiences, that have been suppressed, wishing to free ourselves from these suppressions by the act of re-experiencing. Or even more, we go to the theatre to remember the intense sentiments, which in the past have been our leaders, but have eroded in the dust of time. We go to the theatre to revitalize such sentiments. What we find in drama-if it represents social contexts and struggles is a novel perspective.

\subsection{Sociological Criticism in Literature and Drama}

In the majority of sociological studies, for each and every work of art, two sources have been intended, on one hand, the outer space or context, in its general sense along with its characteristics, and on the other hand, the creator of the work of art and his/her stance and specific viewpoint, regarding the context of his/her work. One of the most crucial and fundamental attempts has always been to analyze and define the relationships between these two sources.

Lucien Goldman, a leading figure in the sociology of arts and literature, argues that one has no choice but to accept that the artist and his work is not an isolated entity, and the more the artist tries to develop the most abstract idea in his work, the more complete notion is in our hands to find out what aspects of his society has been mirrored in his work. There is no escape in this, he believes.

Lucien Goldman discusses three different types of studies in the sociology of literature. Firstly, the kind of studies that are related to the process of printing, distribution and the reception of the literary work, which is actually a sub-category of positivist sociology, that deals with the analysis of real, palpable data. Secondly, the group that has engaged in studying detailed signs and semiotics of collective consciousness in literary works. A leading figure in this group is Leo Lowenthal, that for instance, has discussed the representation of different professions in a number of works of literature. Finally, the kind of sociology of art that is concerned with the specificities of the sociology of a literary work. This subcategory of sociology believes that a literary work is, without doubt, a collective production as much as being the creation of a single author. He divides this third group to two, more specific subcategories of modern and traditional. The latter relating to those of Madame de Stale and Hippolyte Taine's, and the former to the ones, relating to Marxist theories. This group's attempt has been to make a connection between what goes on in the heart of society as a collective entity and the elite with what is reflected in literary production. The first group will be discussed thoroughly.

\section{Lukacs and the Sociology of Arts and Literature}

\subsection{Lukacs's Significance in the Sociology of Literature}

Goldman believes the true revolution in the sociology of literature happens with Lukacs's arguments, what is then called genetic structuralism, whose significance has been making it possible to make a connection between the sociology of literature and the aesthetics and the dialectics of Marx, Kant, and Hegel. Goldman argues, the core idea of Lukacs's aesthetics is that since the fictional world of a literary work constitutes a whole context, with all its belongings, it represents a unity, and that unity is exactly the element of its aesthetics.

What distinguishes Lukacs among other sociologists is the very simple idea that instead of tearing apart the two elements of a work of literature, that is its representation of the real world and its aesthetics, he believes they are completely interrelated, and the very connection between these two constitutes a valuable literary production, 
that in its own turn can be and should be analyzed. Lukacs does this in a time when all the Marxist theorists neglect the aesthetics of a literary work. He creates a new doctrine in Marxist theories, which Goldman then names as the dialectic aesthetics. The importance of the notion of the dialectic aesthetics is that Lukacs recognized the internal world of a fiction as a united world, which possesses a high level of aesthetics and in its turn, represents the events of the outside world as well. Lukacs makes a strong connection between the abstract-aesthetic constitutive elements of a literary work and its content, that is, the collective consciousness, with the real-world content of the collective consciousness. He values the aesthetics of consciousness in a literary work.

\subsection{Sociology and Arts in Lukacs}

One of the most significant and influential philosophical works of Lukacs is the set of articles in a book, called History and Class Consciousness (1972). Lukacs's crucial significance in the refinement of Marxist theories of criticism in this book has been the modification and adjustment of the defiant leftist party in favor of culture and cultural consciousness.

Contrary to traditional Marxists, like Engels, who believed so much in the defeat of capitalism by the core ideas of the defiant leftist party, for the emergence of a better society, Lukacs believed in a cultural refinement and revolution. He argued that with educating the labor force in order to practice a better culture, capitalism will be defeated.

As opposed to most of the Marxist theorists, Lukacs believed that fictional characters display solely one dimension and usually not the most important one of the fiction's class distinction; this, of course, leads to the fact that a number of more common and less significant characteristics of that fictional work gets under the lenses of analysis in order to deconstruct it class-wise. For instance, in the historical novel, Lukacs argues that the nineteenth-century novels have been to display the demise of the bourgeoisie in Europe, and consequently an escape to the old days. Believing so, one deduces that Flaubert's realism and attending to trivial bits of reality in personal daily lives has actually been a sign of escape, that is the immediate offspring of the petty bourgeoisie.

Another significance of Lukacs's, which separates him from the other Marxist critics and at the same time has saved Marxist theories from deterioration, is his attention to the aesthetics of the form of fiction. On the contrary to the majority of traditional Marxists, he considered the form, a crucial factor of art and the actual reflection of social realism in literature. His attendance to form was far different from that of the formalists'; he argued that the content of what is intended to be shown in fiction is immediately reflected in its form and appearance. In this case, like the majority of Marxist theorists, Lukacs believed that the main concern of literature is the society and its human beings.

The main hazard in traditional Marxism, Lukacs argues, is believing in the existence of a direct connection between the content of ideology and the artistic creation. Such a belief signifies the writers, who have stated critical ideologies. Besides, Marxism has truly directed its attention to class distinction, ideology, and collective awareness in the most mechanical way in a literary work, exactly the way its opponents argue and has neglected the aesthetics of literature.

One of Lukacs's core ideas that has actually constituted the base of his view on the realm of arts and literature, is his reflection theory. In summary, in his thoughts, the understanding of the outside world is only made possible through its reflection in consciousness. A work of art, that is a fictional one in nature, is a mere reflection of the truth, in other words, it has to be, he argued. In fact, he is opposed to the kind of fictional work, which reflects the society in a shallow and identical way, but favors the ones, which thoroughly reflect human society in its utmost depth.

This theory of reflection has been a concept, borrowed from the accumulation of Marx and Hegel's theories in arts, through which Lukacs has attempted to illustrate a harmony between the content and form. Thus, Lukacs's theory revolves around the reflection of the real world and humanity, but as Eagleton points out, the true vessel of ideology in art is not the experimental content, but the very forms of the artistic work. So, the form of the artistic work, is, in fact the reflection of its content, and the content is not illustrated in the work through any vessel, but its form.

Lukacs has been criticized in the sense that he has considered an artistic work, a reflection of social realism, like literature has been degraded to a mirror, reflecting its era passively. On the contrary, Eagleton believes if we are to accept the interference of a creative mind in literature, then we are to admit that the consciousness that is the fruit of literature is not an immediate reflection of the social reality, but the reality, that has been the result of the 
attempts of its creator's mind. To elaborate on Eagleton, an artistic work of art is not the original, untouched reality, but a changed and refined version of it, created by its author, in other words, his ideology.

One of Lukacs's concepts, that he shared with other Marxist theorists, was the concept of objectification. This concept has actually been an offspring of Marx and his doctrines', which focused its attention on economic-based criticism. A significant crisis of the time has been the fact that every single entity-human beings, thought, and ideas, etc. was considered for sale. Thus, every entity had its own price, based on which they were ready to be valued.

In a society, run by objectification, the labor force is considered as an object to be bought. Intelligence and artistic creation likewise are valued based on the present currency; thus, the concept of quality judgment based on depth and value of entities would vanish entirely. Lukacs argues, that believing in the existence of such a system will definitely influence the realm of literature, the reason being the existence of a connection between the social mentality and the mentality that constitute the work of art. Within a capitalist society that everything bears its own price, the search of a protagonist for values is to come across defeat, that is the death of merits and the triumph of currency.

\subsection{Lukacs's Theories in Literature}

Most of Lukacs's attention and attendance, except the times he was tending to direct economic actions, is in literature. During the time that the majority of Marxist theorists have been busy defining and refining the society based on their economic-based doctrines, Lukacs was concerned with arts and literature; concerned to a great degree, that even his ideas in the economic field of refinement, have been built upon his artistic thoughts.

Lukacs has always been an advocate of realism on the confrontation field of modernism in literature. One, of course, has to bear in mind that he was tending to the critical kind of realism in Balzac, Dostoyevsky, and especially Thomas Mann, as opposing to the social realism his counterparts in the Soviet Union's favorite.

Although many have considered Lukacs's stance in the criticism of literature not to be trusted, since he was an advocate of an ideological unstable movement, he considers ideology not as a tool to surround oneself in a room of abstract thoughts, but as a window to view the social and individual reality of life through. He argues: "Every single author's ideology, is a mixture of his experiences, turned into an abstract notion. The significance of ideology is to make possible to view the conflicts of various notions in life in a well-written, well-organized text. Ideology is then, a kernel of feeling, thinking and finally writing truly" (Lukacs, 1974, p. 32).

Lukacs praises the literary works of Balzac, Tolstoy, and Dostoevsky to pinpoint the idea that in their work, we face incidents, in which due to the direct engagement of characters in every-day happening, there are concepts and understanding and discoveries to be seen; which matter. We view incidents, in which characters are fully decisive and active, we identify with them and thus, we experience the same situations as active human beings. On the contrary, there are Flaubert and Zola, whose characters are solely audience to what happens to them, to their lives, thus, they turn into passive images for us to passively look at. We are nothing but viewers.

An assumption, of critical importance in the understanding of Lukacs's analysis of literary works, is his interpretation of the evolution of the epic world into the world of real literature, that is, novel and poem. Lukacs strongly believes that the emergence of novel is due to the transformation of the epic era to the societies, defined by class distinction and hierarchy.

He argues that In Homer's era, societies were unified. With the artistic creation of poem, human beings could stand in the center of the world, signifying the collective tendency and not being against it. With the adjustments that emerged through the formation of societies, people bade farewell to epic poems. The moment there was a society made of people with class distinction, there was nothing to be said by the epic poems. The epic poems were replaced by class distinction narratives. The realistic literature, replaced the peaceful protagonist with the critical, opposing one, a protagonist capable of resolving the shortages and difficulties. The opposing protagonist was to unveil the conflicts in the world of crisis and to attempt overcoming them.

With the employment of Hegel's standpoint, Lukacs calls novel, the bourgeoisie epic, and at the same time, he tends to the concepts of aestheticism and historicism. He says that novel is an artistic genre that in the progression of the bourgeoisie is on the same path of epic. On one side, novel displays the aesthetic characteristics of a narration of a unified world, and on the other side, it faces all the alterities that take place during the bourgeoisie era.

Another significant point in Lukacs's theories is the concept of characterization and the definition of a protagonist in literature and drama. Having a clear structure on the selection and evaluation of characters and defining their relationships with the situations and other characters matters greatly to Lukacs. He argues: "Every 
prominent author classifies his characters based on a definite hierarchy and displays that hierarchy among them, not only to unveil the incidents in the fiction and the author's ideology but also to illustrate where each character stands in his/her relation with the whole fictional world and vice versa" (Lukacs, 1971, p. 23).

He also says: "The potential of characters to achieve self-consciousness in literature matters significantly. No doubt, the methods by which an author transforms a personal experience of his characters to a collective one and the kinds of thoughts he depicts in order to explain that experience, vary. For instance, Othello finally sees the path to his self-consciousness to break down the foundation of his very own existence" (Ibid., p. 24).

\subsection{Lukacs's Theories on the Analysis of Modern Drama}

Drama is a game about human beings and his fate, a game in which God is only the audience. Merely one among the audience, his words and action never tend to interact with those of the actors. He just views, that is all (Lukacs, 1974, p. 152).

Similar to the majority of Marxist theorists, Lukacs begins his tending to drama, by the thought revolving around the refinement of sociological and economic aspects of it. Also, with a new look at the social distinction phenomenon, he believes that drama should be displaying this distinction in each and every society, while the quality of the dramatic text in favor of giving awareness to social classes is of great importance. In his Sociology of Modern Drama, a research led in the first years of the twentieth century, which in turn has been during the primary decades of modern drama, he argues that modern drama is the drama of bourgeoisie.

He begins by this very statement that the drama of that era has depicted a new look and new dimensions as well. He introduces a reason for such a phenomenon, that is the new era in which bourgeoisie has been led to a new situation. Lukacs says: "For the bourgeois, drama in general is the very first offspring of the conflicts among class awareness-consciousness. It is the first time that there is a reason for what they say and do on the stage, that is gaining what they have been denied, gaining freedom and power" (Lukacs, 1974, p. 147).

He then discusses a new concept, which was born in the new drama-modern drama, which is "value judgment". Modern drama is not the stage on which we are to view the conflicts of desires, but, it is where conflicts of ideologies play roles.

Lukacs refers to another concept that is "the present moment", it is when "the past" and "the future", in other words, "not anymore" and "not yet" meet. He says so, to absorb our attention to the state of present in dramatic conflicts. Drama is to illustrate present time, even if it narrates from the past.

Characterization in modern drama has also caught his attention. He argues: "To what degree is the modern human being the doer of his actions? He explains himself in his actions: how much of them is really his?" (Lukacs, 1974, p. 186). He further discusses that the connectivity between human being and his action, is what is illustrated in modern drama, and this is the most actual segment of modern drama.

In Lukacs's ideas, all that modern drama tends to tell us is: "How does a human being commit a tragic action? Is it truly he, himself, doing so? What are his reasons then? The question then rises on the tragic flaw: Is it the character himself, that committed the tragic act, and if it is not so, are we to say that this drama is a tragic one?" (Lukacs, 1974, p. 150). In his thoughts, the constitution of a crime is meaningful only if there is a real link between the crime and the person, who committed it.

In his next steps, he directs our attention to the evolution of the protagonist in the modern drama. He says: "The protagonists in the modern drama are more of a passive kind, they do not act, rather, actions are being done for them and on them. They defend more than attacking anyone. Their heroism is of fear and despair and not of those defiant heroes. Though this concept may seem normal to us nowadays, one must not forget that these were the discoveries of him in the primary years of the twentieth century. "The more the dominant force displays itself as a power from without, the more the core tragic conflict moves towards the inner side of the character, that is a conflict merely in his soul" (Lukacs, 1974, p. 151).

Lukacs attributes three aspects to the modern drama: bourgeoisie, historicism, and individualism. He prioritizes the bourgeoisie aspect of the modern drama over the other two, the reason being its relation to the sociology of drama. The very reason that modern drama is that of historicism and individualism is the relationship between the modern drama and the bourgeoisie. He argues: "This simply shows that the forms depicted by the bourgeoise that were used to defy feudalism have now turned into the dominant ones" (Lukacs, 1974, p. 148).

Lukacs believes that the dominant culture of the society is the culture of the bourgeoisie. Although many argued that this aspect of the bourgeoisie is in contrast with the other two aspects of historicism and individualism, he 
insists on his belief, since these two aspects are rooted in the same culture, which could be then turned into a kind of antagonism.

He thinks the new individualism happens due to a shift between freedom and fatalism. Prior to this time, life was one to be lived, now people's beliefs and horizons have become individual. Primitive ideologies were based on fatalism, and human beings saw themselves as a part of a whole, in harmony. Gradually, various situations in life gave them the opportunity to emerge with one's individualism. The mightier the power of fatalism to kill the individualism, the more in tragedies it was illustrated as a dramatic component. Then, of course, human being saw himself to defy this force, even in terms of his own destruction.

\section{All My Sons}

\subsection{A Summary}

All My Sons is a dramatic portrayal of a factory owner-Joe Keller, who sells warlike machinery to the American army, in spite of his knowledge of their deficiency, thus leading to the death of twenty-one young pilots. He releases himself from admitting to the crime, by attributing the fault to his partner and foreman; thus, he becomes the reason of their imprisonment. Larry, Joe's son kills himself on the account of knowing the truth. Gradually, the mystery unveils, Joe has to confess and kills himself eventually.

Christopher Bigsby argues: "This [play] is also about betrayal, about fathers and sons, about America, about self-deception, about fake piety, about egotism, that illustrates itself under perfectionism, about fear of death, about sins, about family life as a prison, about the distinction between the truth and pretention, about the nature of what lies beyond words, about denial, about suppression, about a kind of despair well interwoven within hope, about money, about a kind of existence that resists against our longings, about the longing for innocence, when it is innocence that commits murder, about the eras we live in and about the human beings we want to believe we are, about the fragility of what we believe as truth, about time as our enemy and as a force to defy us..." (Bigsby, 1997, p. 51).

\subsection{Lukacs in All My Sons}

What matters the most to Lukacs in a literary work, is the extent to which the plot and the characters display what is going on in the same society. Based on what was said, he believed in a realistic method of narration, so the symbolic and abstract trend in literature has never caught his interest. The first notion that is shared in Miller and Lukacs's beliefs, is Miller's critical view on the society; this is paralleled with Marxism's trend in the process of people's awareness of class distinction.

As mentioned before, in the experience of an artistic work, Lukacs favored the potential of a link between the abstract-aesthetic constitutive elements of it and its content, that is the collective consciousness with the real-world collective consciousness. He believed that collective consciousness does not exist without individual consciousness. In All My Sons, it is clearly seen that the sociological layer of it does not attempt to reflect the content of collective consciousness, but to show the structure that is the skeleton of the society, the structure, which then leads to the unveiling of the collective consciousness in the society. The experience that Joe Keller and his family go through is actually the spirit of a collective experience in America and probably in the world.

What Miller provides in his play is a social potential, the potential of a collective consciousness through an experience, that is the fruit of the very same society. In other words, though it is a fictional experience, it represents a possible experience for anyone, for everyone to set out a map for a potential of a collective consciousness.

What Lukacs valued was the process of consciousness through a cultural refinement, in which all classes should have taken part. Thus, he had a dual interest in art. The path to consciousness in All My Sons primarily goes through the consciousness of Joe Keller's family. This path is initiated mainly by the remembrance of the time past, the trigger being a moral conflict among the family members.

Since the form of a literary work for Lukacs is not a mere vessel to illustrate the content-essence, the compatibility between his view and Miller's work is also of importance. For instance, the symbolic cut-in-a-half apple tree in the middle of the stage can be interpreted as Joe Keller and his family's moral status, that is corrupted. Another symbolic device that Miller has depicted is the absence of Joe Keller's eldest son, that is the symbol of morality. The family suffers from his absence and there is clearly no way to fill his void but to return to his morals. Thus, Miller's formic creation has been in favor of creating a complicated social system, that has to be communicated through the small world of the play. 
Individualism is another notion, which Lukacs tends to. It is the uniqueness of the individual experience, that can, in turn, represent a collective one. Although Joe Keller and his experience seem pretty specific, in another sense it can be seen as the experience of any other man of the middle class in America. A man, who struggles to achieve the American dream, also has to take a side in the moral conflicts he gets into.

In his theory of reflection, Lukacs prioritizes the presence of the author's critical view in his narration of the society's image to a neutral narration identical with the real incidents of a society. Similarly, Miller never attempts to describe the exact sociological-economic accounts in his society, instead, he portrays a simple image of a family in a specific time and place. By doing so, and by the aid of a couple of artistic references, he succeeds in conveying the spirit of a collective experience, due to the morality crisis, consequent to the corrupted economic system of the time.

As Lukacs has said, the drama is the play of people in front of gods, who do nothing but watch. What matters to Lukacs in this play, is human beings' action against his fate. It does not matter whether he wins against the gods or not, what is of great importance in his consciousness of where he is, what he does, who he is. In All My Sons, Joe, a member of the bourgeois, has turned into a figure, confronted by the very same social class' beliefs and ideas. Joe Keller and his defeat is where the unreal-abstract of the bourgeoisie sees its real-practical portrayal. Whether he wants it or not, he has to, he is made to confess, and it is through his confession that the kind of social consciousness that Lukacs values, takes place.

Lukacs believes that modern drama is that of the bourgeoisie. Miller has displayed a family life of this very class, along with their hopes and longings, as well as their sorrows and consequents of their wrong deeds. Although their experience of life is an individual one, their hopes and distresses are of the human beings of the modern era.

Historicism is an aspect Lukacs discusses on the modern drama. He meant that whatever characteristic the modern protagonist possesses now is a result of the historical experiences of his time and the time past. The situation in which Joe Keller and his family are captured is not solely a situation related to the post-war era, but most of the elements constituted this image have their references to the past. Joe Keller, for instance, is a character made up of a whole historical survey.

Individualism is another factor Lukacs cares about in modern drama. To Lukacs, individualism is an offspring of historicism. It is historicism that leads human beings to individualism. The protagonist often attempts to fill the void between himself and his fate with his individualism. With the loss of the connections that he had had before with the collective life, the very connections that defined him, now it is on him to find and define himself, probably by the aid of his intuition and beliefs. What leads to Joe Keller's defeat is partly because of his personal definitions of the right and wrong and acting on them. No one can get too judgmental of what he has done to the fullest. It is he himself, the tragic hero, who has to take full responsibility and judge himself and probably act based on it. This is what Lukacs calls individualism.

Finally, Lukacs sees tragedy as a field for the conflicts between the human desire to prove himself and the obstacle he can never get rid of. He believes we can move towards the tragic destiny of the protagonist, only when we have taken him out of his peaceful life and put him on the path of finding his very own personal identity. This process lets the protagonist fully understand his inner identity and the outer obstacles, and reassess his relation with the society with a broader sense. This is the utmost frame that Lukacs has defined for the modern tragedy, that is gaining a true self-consciousness.

In another brief look, as Bigsby has earlier discussed, All My Sons is a tragedy of a man, "who prioritizes survival to morals, individualism to the society, expediency to perfectionism, loyalty towards his family to responsibility toward his society. At the same time, it is also about the lack and losing, the lack of a mutual humanity" (Bigsby, 2005, p. 80). Although Joe Keller takes a stance that is against his society's morality, his wrong doings are actually the result of what the same society. This very same society has encouraged him to do, to get, to achieve. He has broken the rules of this society to achieve as he has been urged to the entities valued by it. He pictured the end of his society's ideology.

\section{Death of a Salesman}

\subsection{A Summary}

The play concerns a salesman-Willy Loman, who has always dreamt of turning into a great salesman, so he could provide his sons financially. Now that he has reached his retirement, so much in debts, there is no choice left for him but to daydream. The protagonist, in Death of a Salesman, has come to a dead end in his old age, thus, takes a psychological journey within his thoughts, his past and the hidden layers of the society. By doing so, he attempts unconsciously to defeat his fate. Though he does not succeed in solving the problems consequent to 
his choices in the past, or probably consequent to sociological, economic backgrounds, he commits suicide in order to solve a portion of his family's financial shortcomings.

What had led Willy through this path for a lifetime is actually the attraction in the depth of American culture and society, that is Gatsby's green light. The American dream, that makes the bourgeois run after a view of the green light all their lives and finally leaves them by the time of death, blind to what life is really about, blind to simple truths around them. Bigsby says: "It is the drama of a man, blind to the love of who are concerned about him while sacrificing himself over an idea, that is a false promise of a golden future" (Bigsby, 2005, p. 123).

\subsection{Lukacs in Death of a Salesman}

Miller's plays are exactly what Lukacs asks for in modern drama; the diminishing of the border between the outside world that attributes a set and unchangeable fate to human beings and the inside world that is he, himself and what he chooses to do is perfectly portrayed in Death of a Salesman. Any human being with his direct or indirect reactions to the world makes the world, thus, the world makes human beings.

Miller has perfectly illustrated the economic status of the society and the voids within it in the post-depression era of the 1930s, the unstable state of education and cultural values. All these elements contribute to a portrayal of a whole society of course. Miller has pinned together pieces of actions and inactions of an American family in the 1940s, and within this huge connection, he succeeded in showing us a greater picture of a society. The story of a father, wandering in his dreams and shortcomings, the story of a son, who cannot locate himself in his society, the story of the other son who is drowning in his so-called freedom, much like an unrestrained world of action, the story of a wife, deprived of the love she deserves and sentenced to bear the affliction of the others' stupidity, that is the story. Though the story portrays a specific experience in a specific time and place, it talks to us of a greater cultural, sociological, economic situation.

We need to tend to Lukacs's question again: What makes a protagonist commit a tragic act? Is it truly he, himself doing so? What are his reasons? Regarding Willy Loman and the tragedy of his death, it needs to be said that it is the sociological grounds that have brought him to this situation. Willy has never attempted to escape the consequences of his choices. The notion in tragedy is that the protagonist has to face the truth of the sociological, economic, cultural situations of his society, find out his relation with this situation and finally take a side.

Regarding what has been discussed before as the collective consciousness, Death of a Salesman is the most precise picture of what Lukacs had in mind, to make a connection between the abstract-aesthetic constitutive elements of a literary work and its content with the real world collective consciousness. From another point of view, the image of class distinction and distance is also one of the themes related to Marxist backgrounds of Lukacs, that also contributes to the collective consciousness.

Let us turn to the formic creativity that has been of great importance to Lukacs. In Death of a Salesman, the utmost level of this formic creativity is seen in the psychological instability of Willy, which is actually the result of the imposed social suppressions on him, that have gradually pushed him over to escape into the inner world of his thoughts, as that is the safest shelter he could find. Mental solitude is what is left for him as a result. This form is actually perfectly in the service of the content of the play; the content then, on one hand, shows the relation between a single person and his society and on the other hand his relation with his very own family and his shortcomings and defeat in being a right, suitable father, and husband to them. The mixture of these two kinds of relations within a perfect formic creativity is a sign of a complete turmoil in the situation of the members of a society.

The concept of reflection discussed fully by Lukacs, has also been gone through by Miller in Death of a Salesman. The story of Willy Loman and his family is a specific account of incidents and choices while representing a social ground in a larger society and broader time. The next thing Lukacs cares about greatly is the possibility within modern drama for the lower class to find a voice of their own. This voice is the ideology that confronts the other flowing ideologies in a society. That is exactly why Lukacs insists that the scene of modern drama has to be a ground for the confrontation of ideologies and not feelings.

The next thing Lukacs talks about in his views is the significance of the present time in modern drama. The events should always revolve around present time, even if they refer back to the past now and then; actions should take place at present time and avoid the portrayal of just an account of feelings regarding the past. The present time, for Lukacs, is when the past and future meet. Willy Loman is tangled in a dramatic crisis, in which his choices in the past and his dreams for future have confronted his present situation. Thus, he takes an action - suicide to provide his family with the future he has dreamt of and punish himself, as a counteract to the wrong choices he has made in the past. 
Regarding historicism in modern drama, Death of a Salesman is full of accounts, resulted from a historical background, with its political, sociological and cultural components. Each of these backgrounds actually goes back to a set of historical events. One of the most significant of these historical events in this play is the economic downturn that America has experienced in the 1930s.

The issue of individualism, that Lukacs tended to as a crucial component of the modern drama, displays itself in Death of a Salesman. Lukacs believed that individualism in modern drama reflects itself in the protagonist's inner world of thought, rather than in the outside world, as in this case, the conflicts are all taking place in Willy's mind. This is exactly what Lukacs calls the conflict of one with his own limitations.

A few other points need to be added then regarding the compatibility of Miller and Lukacs's views on modern drama. Willy is a protagonist tangled in his inner conflicts; thus, attempting to find a way to consolidate his identity. He would never surrender to his fate, even if there are no logical grounds for it, only through being a tragic hero. He thinks he has to leave a dash of his footprint against fate on the path of his life. Now, there is another similarity between Miller and Lukacs, since Miller believes in the awareness of self as the figure of fate in this kind of tragedy. He thinks this kind of consciousness is the main result of a definite fate. If we are to accept that tragedy is a mere result of human fate, that it is to evaluate and destroy oneself due to a weakness against evils of self, and if we are to consider this a moral value of tragedy, then we should accept that tragedy is not just a definite superhuman phenomenon.

\section{Conclusion}

Sociology, from the very old times, has been a vessel, through which philosophical lenses examined human beings and their relations among themselves and with a whole, called society. Arts and literature, then, have always been a component of these relations. Drama as an artistic sociologic field has always displayed the sociological, economic, and cultural aspects of people's lives, in most cases with a critical view. Modern drama thus has moved paralleled with the revolutionary phenomena of the $19^{\text {th }}$ and $20^{\text {th }}$ century, thus building a close link with them, in some cases even acting as a revolutionary device.

Georg Lukacs, as a Marxist theorist, with the distinction of tending to artistic values of modern drama, had had the dream of achieving social consciousness through arts. The concept of social awareness and social consciousness has been, then the core idea in Lukacs's discussion of theories in political sociology, culture, and also in criticism of arts and literature. In his view, whatever that is in relation with society, including arts and literature, has got to follow the ideal of human's awareness of himself. As it was discussed in this article, Lukacs's ideas have been portrayed perfectly in Miller's two plays, Death of a Salesman and All My Sons.

Miller's dramatic narrations in both plays, happen in the intervals between escaping from human responsibility and facing its consequences. In All My Sons and Death of a Salesman, Both Joe Keller and Willy Loman, run away from the acceptance of their past deeds and try hard to justify and even deny what they have done, but, somehow, they cannot escape the shadow of its responsibility that accompanies them. This issue forms a similarity between Miller and Lukacs's views on modern drama, that is the essential need for the portrayal of a social experience, through an individual one, with its own specific dramatic conflicts, along with the necessity of the utmost end, the consciousness of one's self.

The majority of Miller's plays in the 1940s, portray the broken figure of the American dream of perfectionism through limitless industrialization, and thus, provide Americans with financial ease and happiness. Both families, the Lomans, and the Kellers could have led a simple, honest life, provided that they had not been blinded by the image of the American dream. In other words, they lost the chance of experiencing a plain honest life and turned into the victims of false beliefs.

Lukacs attributes a crucial characteristic to modern drama, which is the conflict among ideologies. He thinks the dramatic conflicts among characters in a play has to have a greater ground, the conflict of ideologies. Miller has succeeded in this phenomenon perfectly. He has set a ground on which a general tendency in a society has to face the definite consequences of its practical application in life.

This article has been a brief analysis of the potentials of the portrayal of social phenomena in modern drama. This view and definitely its broader counterparts can be applied to many of the greatest dramatists as well. On the other hand, it might be helpful to the new generations of playwrights, in order to be aware of the fact that how their fellowmen can experience a lifetime in their plays and accounts they narrate, how they can achieve a more thorough glace of their choices and consequences in fictional lives, that is actually their own lives. 


\section{References}

Bigsby, C. H. (1997). The Cambridge companion to Arthur Miller. New York, NY: Cambridge University Press. https://doi.org/10.1017/CCOL052155019X

Bigsby, C. H. (2005). Arthur Miller, A Critical study. New York, NY: Cambridge University Press.

Levi-Strauss, C. (1969). The elementary structure of kinship (J. Bell, \& J. V. Sturmer, Trans.). Boston, MA: Beacon Press.

Lukacs, G. (1971). The theory of the novel. London, England: MIT Press.

Lukacs, G. (1974). Soul and form (A. Bostock, Trans.). Cambridge, England: MIT Press.

Tylor, E. B. (1974). Primitive culture: Researches into the development of mythology, philosophy, religion, art, and custom. New York, NY: Gordon Press.

Weber, M. (2012). The theory of social and economic organization (3rd ed., T. Parsons, Ed., A. M. Henderson, $\&$ T. Parsons, Trans.). London, England: The Free Press of Glencoe.

\section{Copyrights}

Copyright for this article is retained by the author(s), with first publication rights granted to the journal.

This is an open-access article distributed under the terms and conditions of the Creative Commons Attribution license (http://creativecommons.org/licenses/by/4.0/). 